\title{
Ações Afirmativas no Vestibular da UERJ: uma análise do perfil socioeconômico dos candidatos à cota étnico racial
}

\author{
Renata da Fonseca Silva Fernandes ${ }^{1}$ \\ Viviane Maurício Figueiredo Machado²
}

\begin{abstract}
Resumo
Este artigo apresenta um estudo do perfil socioeconômico dos candidatos ao Vestibular pelo Sistema de Reserva de Vagas da Universidade do Estado do Rio de Janeiro - UERJ, na opção por cota étnico racial, tendo por referência o Vestibular 2018. Apresentamos um histórico legislativo que contextualiza o Sistema de Cotas para acesso aos cursos de graduação da UERJ; uma descrição das etapas do concurso e por fim, buscamos caracterizar o perfil socioeconômico e familiar dos candidatos concorrentes pelas cotas étnicos raciais, tomando por base os dados do Questionário de Informações Socioculturais do Exame Discursivo do Vestibular.
\end{abstract}

\section{Palavras Chaves}

Reserva de vagas; Cotas étnicos raciais; Perfil socioeconômico.

Affirmative Actions in the UERJ Entrance Exam: an analysis of the socioeconomic profile of candidates for racial ethnic quota

\begin{abstract}
This article presents a study of the socioeconomic profile of candidates for the Vestibular through the Vacancy Reservation System of the Universidade do Estado do Rio de Janeiro - UERJ, in the option for racial ethnic quota, with reference to the Vestibular 2018. We present a legislative history that contextualizes the Quota System for access to UERJ undergraduate courses; a description of the stages of the competition and finally, we seek to characterize the socioeconomic and family profile of the candidates competing for the racial ethnic quotas, based on the data from the Questionnaire on Sociocultural Information of the Vestibular Discursive Exam.
\end{abstract}

Keywords

Reservation of vacancies; Ethnic racial quotas; Socioeconomic profile.

Artigo recebido: novembro de 2020

Artigo aprovado: dezembro de 2020 


\section{Introdução}

O conhecimento do perfil socioeconômico e familiar dos candidatos que buscam o ingresso na universidade pública pelo sistema de reserva de vagas, se constitui como instrumento de trabalho para os profissionais que atuam diretamente no planejamento e execução dessa política pública. Neste sentido, buscamos ampliar o debate, fornecendo elementos que possam contribuir no conhecimento sobre aqueles que visam alcançar o acesso ao ensino superior através das cotas étnicos raciais. Parte-se da compreensão de que a possibilidade de intervir sobre a realidade, de forma efetiva, se dá no movimento de conhecê-la e analisá-la.

O compromisso proposto toma maior relevância ao se tratar dos candidatos que se declaram negros carentes, tendo em vista o componente histórico de discriminação racial sofrido por este grupo na sociedade brasileira, persistente ainda nos dias atuais.

A construção deste trabalho é resultado de nossa experiência profissional atuando na Comissão de Análise Socioeconômica do Vestibular da UERJ e das reflexões produzidas durante a nossa participação no curso de extensão “Ações Afırmativas e Políticas Públicas”, vinculado ao Programa de Desenvolvimento e Educação Theotonio dos Santos/ IFCH/UERJ. A elaboração teve como perspectiva teórico-metodológica a matriz crítico dialética, a partir da abordagem quali-quantitativa. A construção e as reflexões sobre o perfil socioeconômico dos candidatos ao Vestibular Estadual se deram a partir da análise interpretativa da síntese dos dados fornecidos pelo "Questionário de Informações Socioculturais" respondidos pelos candidatos do Vestibular Estadual ao Departamento de Seleção Acadêmica - DSEA/UERJ, conjugada à pesquisa bibliográfica e documental referente à temática.

\section{Marcos normativo e legislativo do sistema de reserva de vagas - contextualizando o acesso à graduação por cotas na UERJ}

Pioneira no acesso ao ensino superior através do Sistema de Reserva de Vagas, a UERJ tem atendido a diversos segmentos de cotas, 
pautada em parâmetros legislativos e normativos que orientam a execução de todo o processo de seleção por cotas do Vestibular Estadual.

A Lei Estadual $n^{\circ} .4 .151^{3}$ datada de 04 de setembro de 2003 marca o início desse processo e instituiu o sistema de cotas para ingresso nas universidades públicas estaduais de todos os candidatos às vagas reservadas tomando como primária a condição de carência socioeconômica. Institui-se também, que fica reservada à universidade defınir e disciplinar a avaliação da condição de carência, com base em indicadores socioeconômicos e ainda, como se fará a prova de tal condição.

No ano de 2007 foi promulgada a Lei Estadual $n^{\circ}$. 5.074 de $17 / 07 / 2007$, onde houve a inclusão de mais um segmento de cota representado por filhos de policiais civis e militares, bombeiros militares e inspetores de segurança e administração penitenciária, mortos ou incapacitados em razão de serviço, no percentual de 5\% destinados a pessoas com deficiência e integrantes de minorias étnicas.

No dia 11 de dezembro de 2008 foi aprovada a Lei Estadual nº 5.346, que substitui as leis anteriores, porém não há alteração da condição de carência socioeconômica como critério primário para acesso às vagas destinadas ao Sistema de Reserva de Vagas.

Como principais mudanças nesta lei podemos pontuar a manutenção do sistema de cotas por 10 anos; a concessão de uma bolsa auxílio durante todo o curso; a alteração no perfil dos estudantes da rede pública de ensino, que passa a abarcar todos os estudantes que cursaram o a partir do $6^{\circ}$ ano do ensino fundamental em qualquer unidade de ensino público do país e não apenas aqueles que cursaram no Estado do Rio de Janeiro. E, por fim, a junção das cotas de negros e indígenas.

Após 10 anos da Lei Estadual 5.346, é sancionada em 27 de setembro de 2018 a Lei 8.121. Esse novo e atual texto mantém a critério de carência socioeconômica como condição primária para o acesso às vagas por cotas e mantêm a autonomia universitária para disciplinar e definir os parâmetros para a avaliação da condição de carência dos candidatos. 
Outros pontos relevantes definidos pela Lei 8.121 são: a fixação do valor da bolsa auxílio paga aos estudantes cotistas durante todo o curso com limite mínimo de meio salário mínimo vigente; inclusão do segmento de cotas para alunos oriundos de comunidades quilombolas no percentual de vagas reservadas a negros e indígenas. E, a alteração do perfil do candidato considerado como oriundo da rede pública de ensino, que passa a ser o estudante que tenha cursado integralmente apenas todo o ensino médio em escolas públicas de todo o território nacional.

Para que possam concorrer a essas vagas os candidatos ao Exame do Vestibular Estadual precisam participar das etapas do processo que se dão ao longo do ano e são divididas em Exame de Qualificação - essa etapa acontece duas vezes no ano com a aplicação de prova composta por questões de múltipla escolha - e o Exame Discursivo que é realizado com a aplicação de apenas uma prova, composta por questões discursivas. Essa é a última etapa do processo de seleção.

É no ato da inscrição do Exame Discursivo que o candidato faz sua opção pelo curso e pela concorrência através das cotas. A partir desse momento dá-se início a avaliação documental realizada pelas comissões de análise socioeconômica e comissões de cotas estabelecidas pela UERJ. As comissões buscam identificar se o candidato atende aos critérios de carência socioeconômica e os critérios estabelecidos para a opção de cota, definidos pelo edital do concurso.

A definição atual do percentual de acesso pelas cotas aos cursos de Graduação da UERJ é: 20 \% para estudantes negros, indígenas e alunos oriundos de comunidades quilombolas; $20 \%$ para estudantes oriundos da rede pública; $5 \%$ para pessoas portadoras de deficiência e filhos de policiais civis, militares, bombeiros e de inspetores de segurança e administração penitenciária, mortos ou incapacitados, em razão de serviço.

\section{Ponderações acerca das vagas destinadas ao segmento de cota étnico racial do vestibular estadual}

Conforme descrito anteriormente, está previsto a reserva de $20 \%$ das vagas do vestibular para autodeclarados negros, indígenas e quilombolas. 
Porém, ao longo de quase duas décadas dessa ação afırmativa implementada no âmbito da UERJ, uma constante é o baixo percentual de ocupação dessas vagas pelos candidatos optantes às cotas étnicos raciais. Tomando como base os dados publicados no Relatório Estatístico pelo Departamento de Articulação, Iniciação Acadêmica e de Assistência e Inclusão Estudantil - DAIAIE, considerando os dados dos anos de 2004 a $2019^{4}$, podemos identifıcar que a taxa média de ocupação dos candidatos que acessam a Universidade pela opção de cota ético racial é de 11,38\%, tendo o ano de 2004 com a maior taxa de ocupação das vagas com 16,45\% e o ano de 2018 com a menor taxa do período com 8,89\%.

Observando o quadro de relação candidato/vagas do Vestibular 2018 divulgado na página oficial do Vestibular Estadual, dentre os 63 cursos que ofertaram vagas para cotas éticos raciais, somente 5 cursos apresentaram um coeficiente maior que 1,5 entre a relação candidato/ vaga $^{4}$. E, de outro lado, 55 cursos (87\%) tiveram o índice de relação candidato/vaga menor que $1,0^{6}$.

Analisando a relação candidato/vaga dos vestibulares de anos anteriores observamos uma tendência de diminuição do coeficiente da média geral entre as vagas ofertadas e o número de candidatos inscritos para as cotas étnico raciais. Esses dados revelam uma questão importante: a baixa demanda de candidatos para esta opção de cota em relação ao quantitativo de vagas ofertada, resultando a não ocupação dos $20 \%$ das vagas reservadas para pretos, pardos e indígenas no Vestibular Estadual.

Os dados referentes à baixa taxa de ocupação das vagas para cota étnico racial do Vestibular Estadual, à primeira vista, nos parecem incongruentes se tivermos como referência os dados estatísticos da sociedade brasileira. Segundo a Pesquisa Nacional de Amostra de Domicílio - PNAD contínua de 2019, a população brasileira era constituída por $56,2 \%$ de pessoas que se autodeclararam pretos ou pardos. No Estado do Rio de Janeiro a população que se autodeclarava preta ou parda era de $13,9 \%$ e $40,2 \%$, respectivamente, somando $54,1 \%$ da população. 
Quanto à distribuição de renda, segundo a PNAD contínua de 2018, o rendimento médio domiciliar per capita para a população preta ou parda era de $\mathrm{R} \$ 934,00$, inferior ao salário mínimo do ano ( $\mathrm{R} \$ 954,00$ ). Essa mesma pesquisa indica que o rendimento médio mensal das pessoas pretas e pardas são, respectivamente, $27,5 \%$ e $25,5 \%$ inferiores em relação à média nacional, enquanto para as pessoas brancas o rendimento médio mensal é $29,9 \%$ superiores a essa média.

Estes dados apresentam apenas alguns indicadores que apontam para a assertiva de que a população no Brasil e também no Estado do Rio de Janeiro é constituída de uma grande parcela de pessoas negras e com baixos rendimentos ${ }^{7}$. Sendo essas as condições necessárias para concorrer a uma das vagas reservadas para pretos e pardos no Vestibular da UERJ, não nos parece razoável o baixo número de candidatos, em relação às vagas, concorrendo pelas cotas étnico racial no Vestibular.

Compreender a realidade por trás desta questão não é o foco deste trabalho, contudo abre-se um leque de indagações sobre os fenômenos que circundam este fato: a população negra tem conhecimento efetivo sobre a política de reserva de vagas por segmento de cota étnico racial existente na UERJ? O debate étnico-racial e as cotas têm alcançado essa parcela de potenciais candidatos? A possibilidade de participação em um processo de vestibular para uma universidade pública é uma realidade para a maioria da população negra? E qual tem sido, ou qual deveria ser o papel da UERJ em desenvolver ações que propicie maior participação de candidatos concorrentes pelas vagas de cotas étnico-raciais?

Não é nosso objetivo, nem é nossa pretensão responder tais questionamentos neste artigo. Contudo, acreditamos que o esforço de conhecer o perfil socioeconômico e familiar dos candidatos que pleiteiam ingressar no ensino superior por meio do processo seletivo desta Universidade, resulte no conhecimento acerca das condições de vida dessa população, possibilitando, assim, vislumbrar ações institucionais que altere de forma efetiva essa realidade. 


\section{Uma análise do perfil socioecômico e familiar dos candidatos às vagas destinadas ao segmento de cota étnico racial do vestibular estadual}

O perfil socioeconômico e familiar ora apresentado é resultado da pesquisa empírica realizada a partir dos dados coletados pelo Departamento de Seleção Acadêmica da UERJ por meio do Questionário de Informações Socioculturais respondidos pelos candidatos na ocasião da inscrição do Exame Discursivo do Vestibular Estadual de 2018.

Foram selecionadas 16 questões dentre o universo de 26 perguntas existentes no questionário, tendo o foco da pesquisa os resultados referentes aos candidatos concorrentes pelas cotas étnico-raciais ${ }^{8}$. As questões selecionadas foram agrupadas em duas categorias de análise: a) acesso e condições de educação e cultura e b) inserção no mundo do trabalho e renda. E, de forma complementar, recorremos ainda, aos dados relativos à descrição da população, divulgado também pelo DSEA, denominado "Dados descritivos por tipo de vaga" referente ao Vestibular de 2018.

Com base na tabulação dos dados descritivos, entre os candidatos inscritos na opção de cota étnico racial, observamos uma maior participação do gênero feminino, 63\%. Quanto à faixa etária temos: entre candidatos de 15 a 17 anos de idade a presença de apenas 1,1\%, seguido dos candidatos com idade entre 18 a 20 anos com 46\%, entre 21 e 23 anos $25 \%$ e com mais de 23 anos 27,1\%. Dessa forma, temos a prevalência de candidatos com idade maior de 21 anos, os quais somam $52,2 \%$ do total de candidatos.

A priori, esse dado não se apresenta como uma questão, considerando que um estudante, inserido adequadamente nas etapas da educação, a faixa etária para estar no curso superior seria entre 18 e 24 anos. Porém, se observarmos a participação dos candidatos concorrentes pela ampla concorrência, identificamos que $72,7 \%$ destes encontram-se na faixa etária entre 18 a 20 anos de idade. Dito isso, a faixa etária dos concorrentes ao Vestibular por cotas étnico-raciais se comparados aos candidatos de ampla concorrência parecem elevadas, evidencian- 
do uma distinção do perfil etário daquele grupo, marcando de maneira diferenciada o perfil dos candidatos autodeclarados negros que optam em concorrer por cotas étnico raciais nessa Universidade.

\section{a) Acesso e condições de educação e cultura}

Para a construção desta categoria foram selecionadas $9^{9}$ perguntas do Questionário de Informações Socioculturais, além de dois dados obtidos nos dados descritivos por tipo de vaga do Vestibular.

Tomaremos como base para refletir sobre os dados do perfil educacional e cultural dos candidatos concorrentes pelo sistema de cotas étnico raciais da UERJ o conceito de capital cultural desenvolvido por Pierre Bourdieu (2003), o qual compreende que os processos educacionais, que se dão no contexto da sociedade de classes, estão diretamente relacionados ao nível cultural da família e o meio social o qual o indivíduo se insere.

Segundo as informações prestadas pelos candidatos, dos que estudaram no Estado do Rio de Janeiro, 63\% declaram ter concluído o ensino médio em escola pública e 32\% em escola particular. Quanto ao turno, o qual cursou a maior parte do ensino médio, a maioria dos candidatos sinalizou o turno diurno, 91\%.

Em relação ao ano de conclusão do ensino médio, 26\% dos candidatos estavam concluindo o último ciclo da educação básica em 2017. Dentre os que já haviam concluído o ensino médio, 20\% informam conclusão no ano de 2016, 9\% tanto para o ano de 2015 quanto para o ano 2014 e 35\% declaram ter concluído o ensino médio em anos anteriores a 2014. Desta forma, inferimos que parte significativa, $44 \%$ dos candidatos concorrentes pelo segmento de cotas étnicos raciais apresentam um interstício de no mínimo quatro anos entre a conclusão do ensino médio e a possibilidade de ingressar no ensino superior. Se compararmos esse mesmo indicador referente aos vestibulares de anos anteriores, percebemos uma constante neste espaço de tempo entre ano de conclusão e a participação no Vestibular, conforme gráfıco 1. 
Gráfico 1. Ano de conclusão do Ensino Médio - comparação entre os vestibulares estaduais
de 2013 a 2018
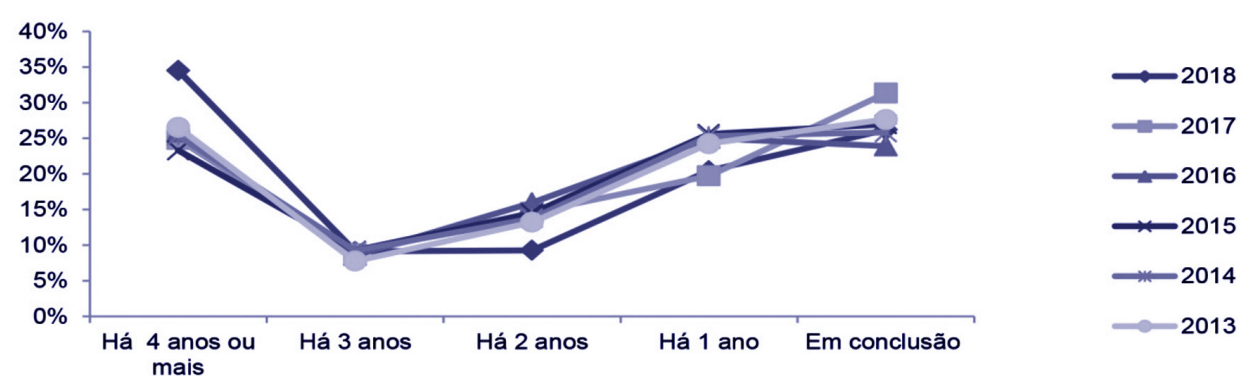

$-2016$

$-2015$

$-2014$

4 anos ou Há 3 anos

Há 2 anos

Há 1 an 2013

Fonte: Dados estatísticos do DSEA - descrição da população dos vestibulares 2013 a 2018.

A diferença temporal persistente entre a conclusão do ensino médio e a participação desses candidatos no processo seletivo do Vestibular explica, em certa medida, a concentração de candidatos por cotas étnico-raciais que apresentam idade maior de 21 anos. Relativizando a ideia de que a idade elevada desse grupo poderia ser consequência de repetência ou evasão escolar e expõem uma questão paralela: a problemática do acesso da população negra ao ensino superior.

Mais da metade dos candidatos, 61,7\% informam frequentar ou ter frequentado curso pré-vestibular, não há, entretanto, dados sobre a natureza do pré-vestibular informado ${ }^{10}$. Em relação se frequenta ou frequentou algum curso de língua estrangeira, por pelo menos um semestre completo, onde os resultados para candidatos pelas vagas reservadas ao segmento étnico-racial são: 47\% não frequentaram e 53\% frequentaram. Esse dado deve ser observado em associação a outros indicadores relativos às possibilidades de acesso à cultura e educação extraescolar.

No questionário é indagado ao candidato a quantidade média de livros não didáticos lido por ele no período de 1 ano. O resultado não apresenta disparidades entre os candidatos por cota étnico-racial e de ampla concorrência. Entre aqueles, 43\% informam ter lido menos que 5 livros, 40\% leram entre 5 e 10 livros. E, entre os candidatos da ampla concorrência 44\% informam ter lido menos que 5 
livros, 37\% leram entre 5 e 10 livros. Porém, quando a questão toca no elemento acesso, esses dados apresentam variações importantes conforme apontado no gráfico 2 , onde $40 \%$ dos candidatos de ampla concorrência informam possuir mais de 51 unidades de livros em sua residência e de outro lado $77 \%$ dos candidatos por cota étnico racial afirmam possuir até 50 livros.

Gráfico 2. Quantidade de livros, aproximadamente, que há na casa do candidato excetuando-se os livros didáticos

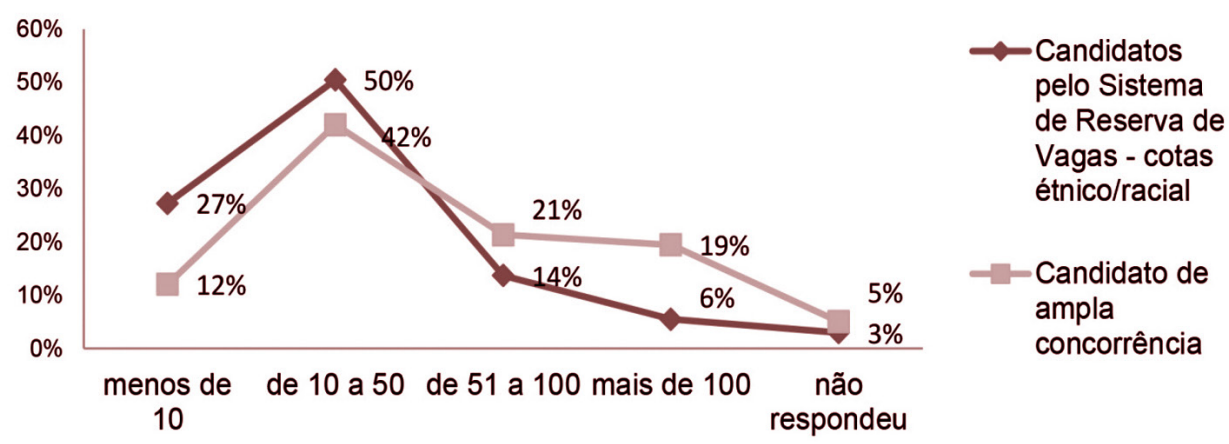

Fonte: Síntese dos dados do Questionário de Informações Socioculturais - vestibular estadual 2018.

Ao pensar na leitura como processo de construção de conhecimento e cultura, a questão do acesso a esse instrumento configura-se como fator facilitador desse processo. $\mathrm{E}$, nesse processo que o âmbito familiar exerce um papel fundamental. O nível de instrução educacional e cultural dos pais permeia o ambiente de convivência familiar e influi, tanto nas suas oportunidades, como também nas possibilidades de escolaridade. Para Bourdieu,

"vê-se nas oportunidades de acesso ao ensino superior o resultado de uma seleção direta ou indireta que, ao longo da escolaridade, pesa com rigor desigual sobre sujeitos das diferentes classes sociais. (...) Na realidade, cada família transmite a seus filhos, mais por vias indiretas que diretas, um certo capital cultural e um certo ethos, sistemas de valores implícitos e profundamente interiorizados, que contribui para definir, entre coisas, as atitudes face ao capital cultural e à instituição escolar." (2003, p.41) 
Nesse sentido, podemos inferir que a herança cultural adquirida pelo sujeito está ligada ao nível cultural dos pais para além das condições de aprendizagem escolar, que na sociedade de classes, configura-se como instituição que legitima e é legitimadora da cultura burguesa dominante. Essa bagagem cultural fornece, àqueles historicamente favorecidos, maiores possibilidades de êxito escolar. Nesse caso, o capital cultural favorece aos candidatos que os possui, resultando em melhores resultados no acesso ao ensino superior.

Partindo dessa premissa e complementando-a, identificar o nível de escolaridade dos pais assume um peso significativo na construção do perfil socioeconômico e familiar desses candidatos. A tabela 1 apresenta dados comparativos entre a escolaridade dos pais, dos candidatos por cotas étnicos raciais e dos candidatos de ampla concorrência.

Tabela 1. Nível de escolaridade dos pais dos candidatos de segmento de cotas étnicoraciais e candidatos de ampla concorrência

\begin{tabular}{lcccc}
\hline & \multicolumn{2}{c}{$\begin{array}{c}\text { Candidatos de segmento } \\
\text { de cotas étnico-raciais }\end{array}$} & \multicolumn{2}{c}{$\begin{array}{c}\text { Candidatos de ampla } \\
\text { concorrências }\end{array}$} \\
\hline mãe & pai & mãe & pai \\
\hline Ensino fundamental & $33 \%$ & $36 \%$ & $12 \%$ & $14 \%$ \\
\hline Ensino Superior & $51 \%$ & $46 \%$ & $34 \%$ & $36 \%$ \\
\hline Não respondeu & $13 \%$ & $9 \%$ & $52 \%$ & $46 \%$ \\
\hline Total & $3 \%$ & $9 \%$ & $2 \%$ & $4 \%$ \\
\hline
\end{tabular}

Fonte: Síntese dos dados do Questionário de Informações Socioculturais - vestibular estadual 2018.

A partir da observação dos dados, alguns pontos chamam nossa atenção. Primeiro, a baixa escolarização dos pais dos candidatos por cotas étnicos raciais. Esse dado revela uma realidade da nossa sociedade e segue os indicies apresentados pela PNAD Contínua publicada em 2019, onde no Brasil e no Rio de Janeiro cerca de 42\% e 50\% respectivamente, da população negra possuía até o ensino fundamental completo, explicitando em números o racismo que se manifesta também em desigualdade educacional. (ALMEIDA, 2019) 
Outro dado alarmante que se apresenta é a discrepância entre o nível de escolaridade dos pais do grupo de candidatos por cotas étnico raciais e os candidatos de ampla concorrência. Observamos que o percentual das mães dos candidatos por cotas com o ensino fundamental é quase 3 vezes maior que o percentual das mães dos candidatos de ampla concorrência. E de forma inversa, o percentual de mães dos candidatos de ampla concorrência com ensino superior é 4 vezes maior do que o percentual da mãe dos candidatos por cota, e em relação ao pai com ensino superior, essa diferença chega ser maior que 5 vezes para os candidatos de ampla concorrência.

Esses dados indicam disparidades relevantes tanto para a questão do acesso, quanto para os níveis de capital cultural presente no âmbito familiar dos candidatos por modalidade de concorrência e expõe a situação desfavorável para o segmento de candidatos concorrentes por cotas étnicos raciais, no que ser refere às possibilidades de acesso ao ensino superior público por meio do vestibular tradicional.

Essa problemática se articula à outra discussão trazida por Bourdieu (2003), sobre as escolhas futuras dos sujeitos estarem orientadas pelas condições objetivas dadas a partir da sua posição na hierarquia social e conversa com duas questões apresentadas no questionário, o qual indaga sobre a escolha do curso de graduação e a relação com suas perspectivas futuras. Quando questionado se a escolha do curso está relacionada a melhores chances futuras de colocação no mercado de trabalho, $80 \%$ dos candidatos confirmam que sim, projetando no investimento educacional a ampliação de seu leque de possibilidades na inserção no mundo do trabalho. Quando questionado se o curso escolhido está relacionado ao acesso a melhores rendimentos, os candidatos não demostram tanta confiança, tendo em vistas o resultado: $47 \%$ não relacionam a formação na graduação pretendida a salários mais altos.

Podemos relacionar esses dados ao menos a dois aspectos que estão direta e indiretamente articulados. Excluindo aqueles que estão concorrendo por vagas em cursos que possuem prestígio social e que 
possibilitam maiores chances de altos rendimentos, temos um grupo que optam por carreiras que a priori, não vislumbram grandes oportunidades de ascensão social por meio da formação profissional. Segundo Bourdieu essa escolha é predeterminada e condicionada subjetivamente à posição que ocupa na sociedade de classes.

Se os membros das classes populares e médias tomam a realidade por seus desejos é que, nesse terreno como em outros, as aspirações e as exigências são definidas, em sua forma e conteúdo, pelas condições objetivas, que excluem a possibilidade de desejar o impossível. Dizer, a propósito dos estudos clássicos em um liceu, por exemplo, “isso não é para nós”, é dizer mais do que “não temos meios para isso". Expressão da necessidade interiorizada, essa fórmula está, por assim dizer, no imperativo-indicativo, pois exprime, ao mesmo tempo, uma impossibilidade e uma interdição. (2003, p.47)

O outro aspecto diz respeito à própria percepção dos jovens e adultos em relação à situação objetiva dos rendimentos proveniente do trabalho no Brasil, em especial para a população negra. Segundo a PNAD contínua - Rendimentos de todas as fontes 2019, em relação à taxa de ocupação com rendimentos, entre os declarados brancos representava 44,8\%, para os pretos e pardos 10,4\% e 43,7\% respectivamente. Apesar da taxa de ocupação com rendimento de pretos e pardos juntos seja maior que dos brancos em 201911, a taxa do rendimento médio mensal para o mesmo ano, denuncia que a inserção dos pretos e pardos, no mundo do trabalho, é precária e com rendimentos mais baixos. O rendimento médio mensal das pessoas pretas e pardas é nesta ordem, $27,5 \%$ e 25,5\% inferiores em relação à média nacional, ao passo que entre as pessoas de cor branca apresentam rendimentos 29,9\% superiores à mesma média. (PNAD, 2019, p.5)

Os dados tratados até aqui e os que serão apresentados adiante, devem ser apreendidos a partir da concepção que o racismo na sociedade brasileira é essencialmente estrutural, o qual opera nas 
bases econômicas, políticas e jurídicas e através delas, como bem discorre Silvio Almeida (2019), e no qual, ainda segundo o autor, "do ponto de vista teórico o racismo, como processo histórico e político, cria as condições sociais para que, direta ou indiretamente, grupos racialmente identificados sejam discriminados de forma sistêmica" (2019, p.51). Dessa forma, o caráter sistêmico do racismo brasileiro espraia por todas as esferas da sociedade e se expressa de forma concreta na vida dos sujeitos como desigualdade educacional, cultural e econômica, como pudemos observar.

\section{b) Inserção no mundo do trabalho e renda}

Para a análise desta categoria foram consideradas as questões relacionas a renda e a ocupação dos candidatos e familiares; assim, foram selecionadas $7^{12}$ perguntas do Questionário de Informações Socioculturais.

Iniciamos com a questão que indaga com quem o candidato mora, a maior parte dos respondeu residir com os pais, seguido de pai ou mãe 82,4\%; sozinho, com parentes ou amigos 9,6\% e 7,8\% com cônjuge. Em relação ao principal responsável pelo sustento do candidato e de sua família, os pais, ou apenas o pai ou apenas a mãe também aparece com resposta predominante, com 78,3\%, seguido da resposta em que o candidato se apresenta como o principal provedor de sua família, com 13,1\%.

Quanto a principal fonte da renda do estudante, $16,4 \%$ dos candidatos informam possuir rendimento advindo do trabalho formal, $13,5 \%$ declaram que sua principal fonte de renda é proveniente de trabalho autônomo, informal, auxílios, pensões ou aposentadorias. E, 67,1\% declaram não possuir nenhuma fonte de renda, sendo esses dependentes do familiar com qual residem.

Partindo de certo conhecimento da fonte da renda dos candidatos concorrentes por cotas étnico-raciais e de sua família, passamos a questão que se refere ao valor mensal bruto proveniente de salários e rendimentos de todas as pessoas que residem com o candidato em salários mínimos (S.M.), obtendo assim a renda mensal bruta da famí- 
lia. Entre os que informam renda familiar até 1 salário mínimo temos $20,5 \%$. A predominância está no grupo que declarou ter renda familiar entre mais de 1 e até 3 S.M. com 58,6\% dos candidatos. E, 15,7\% declararam renda entre mais de 3 S.M. até o limite de 5 S.M. Com percentual menor temos 1,7\% para os que declararam ter renda maior que 5 e até 7 S.M. e 0,1\%, representado por um único candidato, com renda mensal familiar bruta de mais de 10 S.M. até 20 S.M ${ }^{13}$. Nesta pergunta temos um percentual de 3,1\% que não respondeu. O percentual dos que não responderam é 1,8 vezes maior que o percentual de candidatos que declaram renda familiar de 5 até 7 salários mínimos.

De forma previsível, as famílias dos candidatos pela ampla concorrência apresentam melhores condições financeiras e acusam a desigualdade por raça ou cor presente entre os candidatos, assim como nas pesquisas do IBCE já apresentadas.

Os dados referentes à renda familiar dos candidatos concorrentes por cotas étnico-raciais marcam a concentração da renda familiar entre 1 e até 3 salários mínimos. Alinhando essas informações podemos classificar esse grupo como de "famílias de baixa renda", conforme entendimento da legislação brasileira que define essa faixa de renda familiar como critério para inclusão de famílias em Programas Sociais do Governo Federal ${ }^{14}$.

Em relação ao número de pessoas que vivem da renda indicada, temos o menor percentual para o candidato que declara residir sozinho - 8,3\%. Entre os candidatos que declaram duas pessoas temos 18,7\%. Os candidatos que declaram a família composta de 3 e 4 pessoas o percentual é de $28,2 \%$ e $28,7 \%$ nessa ordem. Os que declararam o grupo familiar com mais de 4 indivíduos foi de 15,8\%.

Relacionado a renda mensal ao número de pessoas que vivem da renda declarada podemos inferir uma média da renda per capita mensal do grupo familiar. Assim, podemos supor que a renda per capita média mensal das famílias dos candidatos às vagas por cota étnico racial é de, em média, 1 salário mínimo. Isso quer dizer, meio salário 
mínimo abaixo do patamar de carência socioeconômica estabelecido na legislação vigente para concorrer por cotas na UERJ.

Aliada aos dados sobre renda familiar, as informações sobre a ocupação dos pais, constitui-se como indicador robusto na análise do perfil socioeconômico e familiar dos candidatos concorrentes por cotas étnicos raciais. Aqui trataremos os dados relativos à ocupação principal dos pais apresentados na tabela $2^{15}$.

Tabela 2. Ocupação principal dos pais dos candidatos concorrentes no vestibular 2018 por segmento de cota étnico-racial

\begin{tabular}{lcc}
\hline & mãe & pai \\
\hline Profissional liberal ou empresário(a) & $4 \%$ & $4 \%$ \\
\hline Servidor público ou militar & $9 \%$ & $9 \%$ \\
\hline Empregado(a) no setor privado & $31 \%$ & $40 \%$ \\
\hline Autônomo ou prestador de serviços & $50 \%$ & $40 \%$ \\
\hline Não respondeu & $6 \%$ & $7 \%$ \\
\hline Total & $100 \%$ & $100 \%$ \\
\hline
\end{tabular}

Fonte: Síntese dos dados do Questionário de Informações Socioculturais - vestibular estadual 2018.

Consciente que as possibilidades de respostas não se apresentam da forma mais adequada, pois deixa de fora alternativas que representam a realidade concreta da situação ocupacional dos pais dos candidatos. Nesse sentido, o esforço de análise será feito a partir do alinhamento das complexas questões do mundo do trabalho no Brasil articulando aos elementos empíricos disponíveis a partir da síntese dos dados da ocupação dos pais.

Considerando as respostas possíveis, enunciaremos algumas situações não apresentadas ao candidato e, portanto, os induzem a não assinalar uma das alternativas ou ainda, marcar uma resposta por aproximação. Uma dessas situações refere-se ao grupo composto por aqueles que não estão inseridos no mundo do trabalho: os pais que vivenciam o desemprego, os que se identificam como "do lar" e outras ocupações não remuneradas. 
A segunda situação reúne grupos em condições mais complexas, como os Micros Empreendedores Individuais - MEI. Em um contexto de altas taxas de informalidade ${ }^{16}$, a instituição do MEI visava formalizar, com carga tributária reduzida, diversos trabalhadores por conta própria que não possuíam nenhum amparo legal, jurídico e proteção previdenciária. Temos ainda os trabalhadores informais, composto por aqueles que trabalham por conta própria, não formalizados e não vinculados a nenhum sistema de proteção social e os que realizam atividades eventuais "bicos". Em ambas as situações estes trabalhadores encontram-se em ocupações mais vulneráveis.

Assim, observemos os dados referentes aos que não responderam. Para a mãe e pai dos candidatos por cotas étnicos raciais o percentual de $6 \%$ e $7 \%$ é maior que o relativo à ocupação categorizada como "profissional liberal ou empresário" que aparecem com 4\% para os dois, mãe e pai. De certo, os dados "ocultos" podem estar camuflando situações ocupacionais precárias ou até mesmo a ausência de ocupação.

A categoria dos profissionais autônomos ou prestadores de serviços guardam especificidades particulares. Essas modalidades de relações de trabalho, dada a nova fase da crise estrutural do capital, operam a terceirização da mão de obra através de contratos precários e subcontratos, dissimulando a superexploração da classe trabalhadora (ANTUNES, 2018). Notamos aqui, que a categoria dos profissionais autônomos ou prestadores de serviços representou a ocupação mais frequente para as mães dos candidatos por cotas com o percentual de $50 \%$ e para os pais com $40 \%$, expondo a situação ocupacional desse grupo familiar, principalmente para as mulheres.

A ocupação "empregado no setor privado", compreendendo aqueles com carteira assinada, representam $40 \%$ para o pai e $31 \%$ para a mãe. Resgatando o nível de escolaridade dos pais desses candidatos, qual seja, alta concentração no ensino fundamental e médio, podemos supor uma inserção no mercado formal de trabalho sem altos rendimentos e fragilidade na estabilidade do emprego. Essa é uma caracte- 
rística que marca a mão de obra de baixa qualificação no Brasil. Assim, apesar de acessar algum nível de proteção social, essas famílias estão mais vulneráveis às situações adversas.

O servidor público ou militar são ocupações que representam maior estabilidade e salários mais altos se comparado aos rendimentos médios dos trabalhadores do setor privado brasileiro, esse representa $9 \%$ do percentual tanto para o pai, quanto para a mãe, assim representado na tabela 2 .

A amplitude da categorização da ocupação dos pais dificulta análises comparativas com os dados estatísticos ofıciais, inviabilizando relações mais intrínsecas entre os resultados. Contudo, o estudo dos dados permitiu caracterizar o perfil ocupacional dos pais desses candidatos frente às particularidades do mundo do trabalho no Brasil. Percebemos a fragilidade das famílias dos candidatos autodeclarados negros diante das transformações constantes no mundo do trabalho. Tal condição repercute na condição de renda e moradia, com implicações no acesso à educação e a cultura. Recorremos a Abdias do Nascimento, que de forma didática, expõe o complexo processo histórico de discriminação racial no Brasil.

Se os negros vivem nas favelas porque não possuem meios para alugar ou comprar residência nas áreas habitáveis, por sua vez a falta de dinheiro resulta da discriminação no emprego. Se a falta de emprego é por causa de carência de preparo técnico e de instrução adequada, a falta desta aptidão se deve à ausência de recurso financeiro. Nesta teia o afro-brasileiro se vê tolhido de todos os lados, prisioneiro de um círculo vicioso de discriminação - no emprego, na escola - e trancadas as oportunidades que permitiriam a ele melhorar suas condições de vida. (1978, p.85)

Munanga ressalta a educação e a formação profissional e intelectual, de qualidade, como a possibilidade de mudança real das condições de vida da população negra a partir do acesso com representatividade nos cargos centrais de tomada de decisão do país. Assim, a 
política de cotas seria uma das pontes para esse processo e o rompimento desse círculo vicioso. (2010, p.24).

Evidenciamos até aqui que o preâmbulo da discussão do acesso ao ensino superior público pelo vestibular é marcado tanto pelas condições econômicas quanto pelas condições educacionais e culturais dos candidatos. Os dados apresentados não podem ser destacados do contexto macro da sociedade e de seus processos sociais. O processo seletivo por meio do sistema de vestibular não está apartado deste contexto. Assim, podemos dizer que o próprio processo de seleção em si reflete a imagem da sociedade o qual está inserido e reverbera os traços marcantes da desigualdade racial presentes na sociedade brasileira por meio dos candidatos, em especial os autodeclarados negros e indígenas, concorrentes às vagas por cotas étnico-racial.

\section{Considerações finais}

Diante do perfil socioeconômico e familiar dos candidatos por cotas étnico-raciais apresentado, as políticas de ações afırmativas que visam garantir o acesso ao ensino superior público por meio das cotas, se impõem como legítimas e necessárias em prol da promoção da população negra, que historicamente foi preterida de todo tipo de direito e impedida de acesso à bens e serviços públicos.

Ao longo da análise dos dados apresentados podemos perceber que o debate étnico racial no que se refere à política de reserva de vagas na UERJ é perpassado não só pelas características próprias do processo do vestibular, mas pelas condições impostas historicamente à população negra na sociedade brasileira. Estas barreiras estão relacionadas ao racismo estrutural sistêmico, presente em todos os espaços da sociedade e que se apresenta como negativa de direitos e serviços para a população negra, no campo da educação, cultura, saúde, habitação, trabalho, renda, entre outros. O racismo também reflete na construção e na implementação dessa política pública afırmativa de acesso ao ensino superior, voltada ao segmento étnico e racial. 
A luz dessa reflexão pode-se identificar que, apesar de pioneira, com mais de 17 anos de efetivação da política pública de acesso por meio de vagas reservadas à população negra, a UERJ ainda se depara com o não preenchimento total das vagas destinadas à cota étnico-racial para os cursos de graduação. Dessa forma, o compromisso com o fortalecimento e ampliação dessa política pública de ações afırmativas impõe a Universidade que se adote uma ação proativa no sentido de promover a ampla participação dos potenciais candidatos a concorrerem pelas vagas destinadas aos negros, indígenas e com a atualização da legislação, também os quilombolas.

Trazer a pauta das cotas étnico raciais à discussão é falar não somente do acesso dos negros e indígenas no ensino superior, mas também, discutir os processos e as barreiras a serem enfrentados para a garantia da ocupação efetiva das vagas que lhes são reservadas por direito através da política de cotas étnicos raciais.

\section{Referências}

ALMEIDA, Silvio Luiz de. Racismo Estrutural. São Paulo: Sueli Carneiro; Pólen, 2019. ANSILIERO, Graziela. COSTANZI, Rogério Nagamine. FERNANDES, Alexandre Zioli. Análise descritiva das políticas públicas de inclusão previdenciária dos trabalhadores autônomos: o plano simplificado de previdência social e o microempreendedor individual. Texto para Discussão - 2546. Rio de Janeiro: IPEA. Março, 2020. Disponível em: https://www.ipea.gov.br/portal/index. php?option=com_content\&view $=$ article $\& i d=35458 \&$ Itemid $=4482020$. Aces so em: 05 Set. 2020.

ANTUNES, Ricardo. O privilégio da Servidão: o novo proletariado de serviços na era digital. São Paulo: Boitempo, 2018. Parte I, II.

BOURDIEU, Pierre. A escola conservadora: as desigualdades frente à escola e à cultura. In: NOGUEIRA, Maria Alice; CATANI, Afrânio (Org.). Escritos de educação. Petrópolis: Vozes, 2003. p. 41-64.

DAIAIE (UERJ). Sistema de Reserva de Vagas em números: relatório estatístico 2020. Disponível em: http://www.daiaie.uerj.br/wp-content/uploads/2020/08/ Relato\%CC\%81rio-Estati\%CC\%81stico-Parte-I.pdf. Acesso em: 09 jul. 2020. 
DSEA (UERJ). Questionário de Informações Socioculturais. Disponível em: https://www.vestibular.uerj.br/?page_id=8443. Acesso em: 08 jul. 2020

DSEA (UERJ). Quadro comparativo da relação candidato/vaga. Anos 2013-2018. Disponível em: https://www.vestibular.uerj.br/. Data de acesso em Ago. 2020.

FERNADES, Florestan. A integração do negro na sociedade de classes: (o legado da "raça branca"), volume I - 5. ed. São Paulo: Globo, 2008. p 9-298.

IBGE. Desigualdades Sociais por raça e cor no Brasil. Estudos e pesquisas. Informação demográfica e socioeconômica. n. 41, Rio de Janeiro, 2019. Disponível em: https://biblioteca.ibge.gov.br/index.php/biblioteca=-catalogo?viewdetalhes\&id=2101681 Acesso em: Ago. 2020

IBGE. Rendimentos de todas as fontes 2019. Publicações. Pesquisa Nacional por Amostra de Domicílios Contínua, Rio de Janeiro, 2020. Disponível em: https://biblioteca.ibge.gov.br/index.php/biblioteca-catalogo?view=detaIhes\&id=2101709 Acesso em: Ago./Set. 2020.

IBGE. Educação 2019. Publicações. Pesquisa Nacional por Amostra de Domicílios Contínua, Rio de Janeiro, 2020. Disponível em: https://www.ibge. gov.br/estatisticas/sociais/educacao/17270-pnad-continua.html?edicao=27257\&t=publicacoes Acesso em: Ago./Set. 2020.

IBGE. Características gerais dos domicílios e dos moradores, 2019. Pesquisa Nacional por Amostra de Domicílios Contínua. Disponível em: https://www. ibge.gov.br/estatisticas/sociais/educacao/17270-pnad-continua.html?edicao=27258\&t=resultados Acesso em Ago./Set. 2020.

IBCE. Características gerais do mercado de trabalho, 2019. Pesquisa Nacional por Amostra de Domicílios Contínua. Disponivel em: https://www. ibge.gov.br/estatisticas/sociais/educacao/17270-pnad-continua.html?edicao=28549\&t=resultados Acesso em: Ago./Set. 2020.

IBGE. Rendimentos de todas as fontes 2018. Publicações. Pesquisa Nacional por Amostra de Domicílios Contínua, Rio de Janeiro, 2018. Disponível em: https://biblioteca.ibge.gov.br/index.php/biblioteca-catalogo?view=detaIhes\&id=2101673 Acesso em: Ago./Set. 2020.

MACHADO, I. A. e PAURA, S. G. A atuação do assistente social junto aos alunos oriundos do sistema de cotas na UERJ. Revista Agora: Políticas Públicas e Serviço Social. Rio de Janeiro ano 3, n. 06, abril 2007.

MACHADO, V. M. F. e PAURA, S. G. A Experiência da UERJ com o Sistema de Reserva de Vagas: os 10 anos da Lei Estadual 5.346 de 11 de dezembro de 2008. In: Anais do I Seminário Internacional de Serviço Social na Educação; 
V Fórum de Serviço Social na Educação do GEPESSE: A Educação e o Serviço Social no Contexto de Crise do Capital. UNESP, Franca SP, julho de 2019.

NASCIMENTO, Abdias do. O Genocídio do Negro Brasileiro. Rio de Janeiro: Paz e Terra,1978.

MUNANGA, Kabengele. Cotas raciais na USP, um debate atropelado e "operação abafa". Revista Adusp, São Paulo, n. jun. 2010, p. 20-25, 2010. Disponível em: https://www.adusp.org.br/files/revistas/47/r47a03.pdf Acesso em: 11 set. 2020.

UERJ. Avaliação Qualitativa dos Dados sobre desempenho acadêmico. Relatório - 2011.

\section{Notas}

1 Especialista em Oncologia pelo Programa de Residência Multiprofissional em Oncologia do Instituto Nacional de Câncer (INCA), Assistente Social servidora pública na Universidade do Estado do Rio de Janeiro - UERJ, lotada na PR4 - Pro Reitoria de Políticas e Assistência Estudantis, Brasil, ORCID: 0000-0001-6240-5976 e-mail: renatafonseca_seso@yahoo.com.br.

2 Mestre em Serviço Social pela Pontifícia Universidade Católica do Rio de Janeiro, Assistente Social servidora pública na Universidade do Estado do Rio de Janeiro - UERJ, lotada na PR4 - Pro Reitoria de Políticas e Assistência Estudantis, Brasil, ORCID: 0000-0001-8224-9659, e-mail: vicamauricio@yahoo.com.br.

3 Esta Lei agregou as leis anteriores (Leis Estaduais $n^{\circ}$. 3.524/00 - estudantes da rede pública de ensino, $n^{\circ}$. 3.708/01 - afrodescendentes e $n^{\circ}$. 4.061/03 - pessoas portadoras de deficiência). (MACHADO E PAURA, 2007)

4 Dados calculados a partir do número de alunos ingressantes por cotas informado no Quadro 1, da Parte I - Situação Acadêmica do documento Sistema de Reserva de Vagas em números do Relatório Estatístico - Ano 2020, disponível em http:// www.daiaie.uerj.br/index.php/relatorios/

5 Os cursos que apresentaram coeficiente maior que 1,5 na relação candidato/vaga são: Medicina (7,95), Psicologia $(1,8)$, Direito $(1,7)$, Relações Internacionais $(1,63)$, Jornalismo (1,6), Enfermagem $(1,5)$.

6 Dados obtidos a partir da sistematização das informações divulgadas pelo DSEA, em resultados acadêmicos do Exame Discursivo do Vestibular Estadual 2018, disponivel em https://www.vestibular.uerj.br/?page_id=8358.

7 Para mais informações sobre racismo e desigualdade racial no Brasil, ver: Abdias do Nascimento, 1978; Florestan Fernandes, 2008; Silvio de Almeida, 2019. 
8 As cotas étnico-raciais são destinadas ao grupo de autodeclarados negros e indígenas, conforme as Legislações vigentes. Contudo, neste trabalho, referenciamos as cotas étnico-raciais direcionadas a atender os candidatos concorrentes às vagas reservadas aos negros, já que no processo seletivo em questão, teve como declarados indígenas apenas $0,81 \%$ dos candidatos em estudo.

9 Questões selecionadas do Questionário de Informações Socioculturais: Você cursou o ensino médio, em sua maior parte, em que turno?, Você frequenta ou frequentou algum curso pré-vestibular para o vestibular deste ano?, Você frequenta, ou já frequentou, algum curso livre de língua estrangeira por pelo menos, um semestre completo?, Quantos livros, em média, você lê por ano, excetuando-se os livros didáticos?, Quantos livros, aproximadamente, há em sua casa, sem contar os livros didáticos?, Qual o nível de escolaridade de sua mãe?, Qual o nível de escolaridade do seu pai?, A escolha do seu curso de graduação está relacionada a melhores chances futuras de colocação no mercado de trabalho?, A escolha de seu curso de graduação está relacionado à possibilidade de conseguir salários mais altos em sua futura profissão do que em outras? Dos dados descritivos foram utilizadas as informações do tipo de escola em que o candidato concluiu o ensino médio e o ano de conclusão.

10 Cabe mencionar a atuação da rede de cursos Educação e Cidadania de Afrodescendentes e Carentes (Educafro) e o Pré-Vestibular para Negros e Carentes (PVNC), além de outras organizações civis voltadas para a ampliação de negros e carentes nas universidades, que são responsáveis pela preparação de candidatos para os vestibulares do país por meio de politicas de ações afırmativas.

11 A primeira vista, esse parece ser um dado bastante positivo, porém a publicação "Desigualdades Sociais por Cor ou Raça no Brasil" expõe a outra face da questão: "Assim como no total da população brasileira, as pessoas de cor ou raça preta ou parda constituem, também, a maior parte da força de trabalho no país. (...) Entretanto, em relação à população desocupada e à população subutilizada, que inclui, além dos desocupados, os subocupados e a força de trabalho potencial, as pessoas pretas ou pardas são substancialmente mais representadas - apesar de serem pouco mais da metade da força de trabalho (54,9\%), elas formavam cerca de $2 / 3$ dos desocupados $(64,2 \%)$ e dos subutilizados $(66,1 \%)$ na força de trabalho em 2018". (IBCE, 2018)

12 Questões selecionadas do Questionário de Informações Socioculturais: Qual a principal ocupação de sua mãe?; Qual a principal ocupação de seu pai?; Qual o principal responsável por seu sustento e o de sua família?; Usualmente, qual a sua principal fonte de renda?; Qual é a renda mensal bruta de sua família?; Quantas pessoas de sua família vivem da renda mensal indicada? e Com quem você mora?

13 Considerando que o Sistema de Cotas é reservado para candidatos carentes, o candidato que declara rendimento familiar relativamente alto parece estar ig- 
norando a legislação vigente. Contudo cabe ressaltar, que a carência socioeconômica é definida pela renda per capita familiar, onde, supondo que um grupo familiar possua várias pessoas auferindo renda e igualmente seu grupo familiar é composto de muitos integrantes esta pessoa estará no perfil de carência socioeconômica preconizado na legislação.

14 O Decreto 6.135 de 2007, que dispõe sobre o Cadastro Único para Programas Sociais do Governo Federal, define em seu Art. 4, II-Família de baixa renda, "b) a que possua renda familiar mensal de até três salários mínimos".

15 Em caso de aposentadoria o candidato deve considerar a ocupação na qual a aposentadoria tenha ocorrido, conforme orientação apresentada no próprio questionário. (DSEA, Questionário de Informações Socioculturais, pergunta 21, Vestibular Estadual 2018.)

16 a) "De 2012 para 2019 a proporção de trabalhadores por conta própria passou de $22,8 \%$ para $25,8 \%$. Mantendo trajetória de expansão observada em anos anteriores, o trabalhador por conta própria cresceu 4,2\% (mais 991 mil pessoas), alcançando 24,4 milhões de pessoas, o maior número de toda série" (IBCE, PNAD contínua - renda, 2019 p.2); b) "Em 2018, enquanto 34,6\% das pessoas ocupadas de cor ou raça branca estavam em ocupações informais, entre as de cor ou raça preta ou parda esse percentual atingiu $47,3 \%$. A maior informalidade entre as pessoas de cor ou raça preta ou parda é o padrão da série" (IBCE, Desigualdades Sociais por cor ou raça no Brasil, 2018, p. 2) 